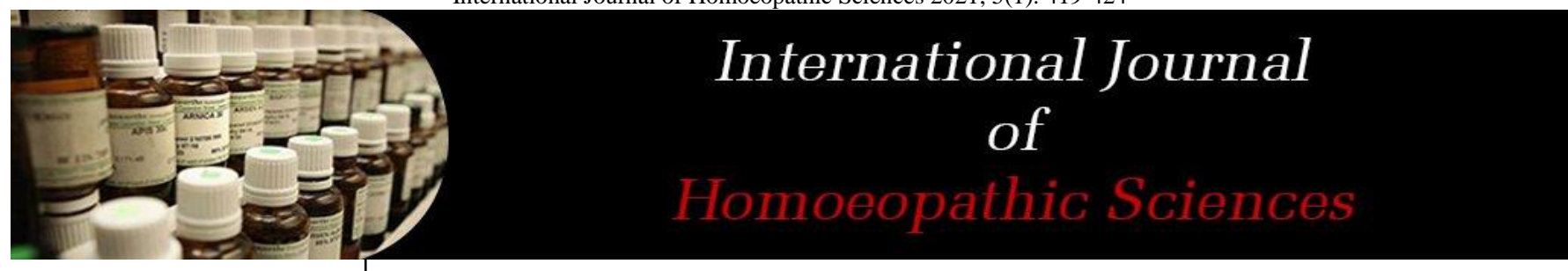

E-ISSN: 2616-4493 P-ISSN: 2616-4485 www.homoeopathicjournal.com IJHS 2021; 5(1): 419-424 Received: 13-12-2020 Accepted: 15-01-2021

Dr. Rajni Gandha Ph.D Scholar, Tantia University, Sriganganagar, Rajasthan, India
Corresponding Author: Dr. Rajni Gandha Ph.D Scholar, Tantia University, Sriganganagar, Rajasthan, India

\section{To identify the factors in the causation of migraine and its homoeopathic management using hit-6 questionnaire}

\section{Dr. Rajni Gandha}

DOI: https://doi.org/10.33545/26164485.2021.v5.i1g.346

\begin{abstract}
Background: Headache is the most common clinical problem in medicine, of which migraine alone affects nearly $15 \%$ of the population worldwide. It is the third most prevalent and seventh leading cause of disability worldwide. According to American Migraine study (AMS-II), there are nearly one in four households having at least one migraine sufferer. It is an individual burden as well as a social burden. Migraines are believed to be multifactorial in its origin and most of them are due to a mixture of environmental and genetic factors.

Thus, in view of increasing prevalence of migraine and the intensity of symptoms, there is a strong need for rapid, gentle and permanent cure of this condition and this can be achieved through Homoeopathy.

Methodology: Total of 30 cases was selected by Purposive Sampling Method. All cases were selected according to inclusion criteria and exclusion criteria. Data was collected from patients, by interviewing the patient about the history of the complaint in detail, the onset, progression etc. For assessment of the clinical status before and after treatment, HIT- 6 Questionnaire was used and Paired t-test was used to test the hypothesis.

Results: The highest prevalence of migraine in this study was found to be among females with 24 cases $(80 \%)$; in the age group of 36-45 years with 16 cases $(53.33 \%)$. Out of the 30 cases considered, $20(66.66 \%)$ were of common migraine; mostly suffered by housewives i.e. 12 cases $(40 \%)$; Natrum muriaticum was the remedy prescribed for maximum number of cases i.e. $15(50 \%)$.

Out of the 30 cases considered, 30 cases (100\%) improved. The statistical analysis also showed significant improvement after the treatment ('p' value $<0.001$ ).

Conclusion: The above-mentioned result is conclusive of the fact that Homoeopathic medicines are very much effective in the treatment of migraine.
\end{abstract}

Keywords: migraine, HIT- 6 questionnaire, precipitating factors

\section{Introduction}

Headache is the most common clinical problem in medicine. Different kind of headaches can have their own causations, set of symptoms and treatment procedures. Frequent headaches can affect relationships and also daily routine.

Among all the types of headache, migraine alone affects approximately $15 \%$ of people worldwide, two-third of who are women. In India, the exact prevalence of migraine is unknown. It is the third most prevalent and seventh leading cause of disability worldwide. According to AMERICAN MIGRAINE STUDY (AMS-II), there are nearly one in four households having at least one migraine sufferer. It is an individual burden as well as a social burden. Around $\$ 13$ billion per year is invested in the treatment of the same.

The earliest reference to the disease is contained in the Ebers papyrus written around 1500 B.C.E in ancient Egypt. The word 'Migraine' is derived from the Greek word - 'hemikrania' which means 'painon one side of the head' ('Hemi'- half and 'kranion'- skull). It was accepted by the French translations as migraine.

It is not always easy to find the exact cause of headache. Migraine is believed to be multifactorial in its origin and is mostly due to a mixture of environmental and genetic factors. The exact course of migraine is unknown. It may result from stretching inflammation or destruction of pain sensitive nerve fibers from trigeminal, glosso-pharyngeal, vagus and upper third cranial nerves.

Homoeopathy believes treating the man as a whole. This system of medicine treatsthe patient from the mental sphere to the physical sphere based on the totality of symptoms with the 
similar medicine taking into account the ailments which produces or provokes the disease condition. Causation is the root cause of the disease and this system takes the person as one entity where number and names of disease does not make much difference to the treatment procedure. This study is a humble attempt at understanding the various factors causing migraine and also to demonstrate the effectiveness of Homoeopathy in it. The detail of all the experiences shall be shared in the further pages.

\section{Objective}

1. To identify the factors in the causation of migraine

2. Efficacy of homeopathic medicines in the treatment of migraine

\section{Materials and Methods}

\subsection{Research design}

This study is a before and afterwithout control, experimental study and design. The result of the study was analyzed using paired and unpaired t-test

\subsection{Source of data}

The subjects were selected from Out Patient Department, In Patient Department and Peripheral Centres of Father Muller Homoeopathic Medical College and Hospital, Mangalore.

\subsection{Sample size}

The sample consisted of 30 cases of Migraine (common or classical) taken by Purposive Sampling Method. All cases were selected according to inclusion and exclusion criteria.

\subsection{Period of study}

The study was conducted on the cases available from April 2016- January 2018

\subsection{Inclusion Criteria}

Both the sexes aged between 18-50 yrs. Of migraine will be selected.

\subsection{Exclusion Criteria}

- Patients who are on other medications (Allopathy, Ayurveda, etc.) for the same complaints.

- Subjects with any other complaints.

\subsection{Method}

- Data was collected from subjects by interviewing and clinical examination.

- All data was recorded in the standardized case record of Father Muller Homoeopathic Medical College.

- Subjects were analyzed using HIT- 6 questionnaire before starting treatment and after 6 months of treatment.

- Once the data was recorded, it was processed as per guidelines adapted in the standardized case record of Father Muller Homoeopathic Medical College.

- A remedy was selected after referring Homoeopathic Materia Medica

- Therapeutic plan was evolved individually for each case.

- The cases were followed for six months.

- There were no control groups used in the study and all the subjects were treated on outpatient basis.
- No concomitant therapy such as Allopathic treatment or any other was used. Subjects, who were already on other therapy, were asked to discontinue the same.

- Selection of remedy, potencies and repetition were as per the requisites of the caseand the degree of correspondence to the remedies.

- Potencies ranging from 30 to $1 \mathrm{M}$ were used. Placebo administration was done in between the two prescriptions for psychological effect.

\subsection{Follow ups}

- Subjects were mostly reviewed monthly. During follow up, each case was evaluated according to the follow up criteria.

- Follow up in each case was planned for a period of one month from the commencement of treatment.

- Corresponding scores were awarded to record the improvement after 6 months of treatment.

\subsection{Assessment of effectiveness}

Effectiveness of the treatment was assessed on the following basis:

- Symptomatic relief in the patient

- Accordingly scoring after six months according to HIT6 questionnaire. These were statistically evaluated

Assessment of the clinical status before and after treatment is analyzed by using Paired- $t$ test with the help of PSPP software version

\section{Observations and result}

30 diagnosed cases of migraine were studied for a period of minimum 6 months. HIT-6 questionnaire scoring was followed in the first visit and after 6 months of the treatment. The following observations were made.

\subsection{Distribution of cases according to gender}

Table 1: Distribution of cases according to gender

\begin{tabular}{|c|c|c|}
\hline Gender & Frequency & Percentage \\
\hline Male & 6 & 20 \\
\hline Female & 24 & 80 \\
\hline
\end{tabular}

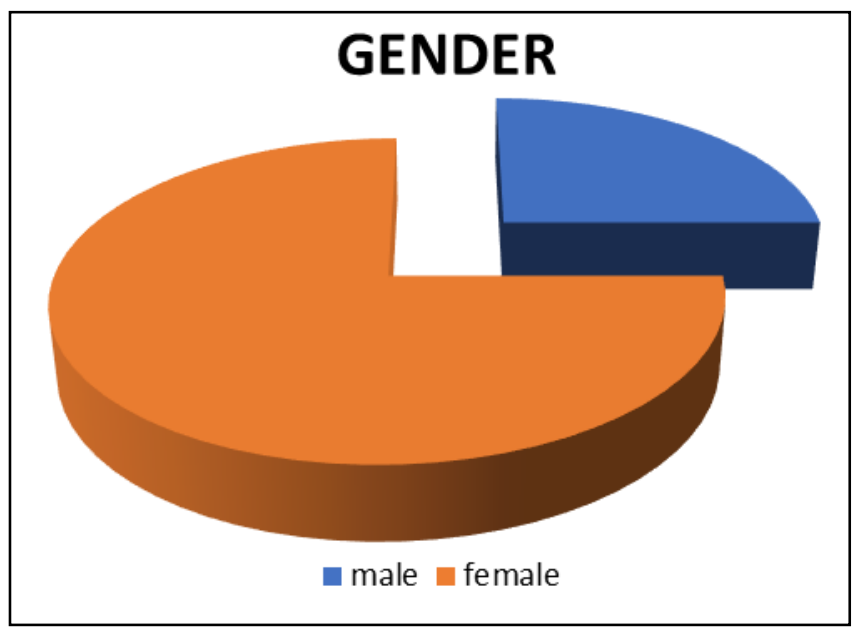

Fig 1: Distribution of cases according to gender

Out of 30 patients, 6 were male (20\%) and 24 female (80\%). 


\subsection{Distribution of cases according to age group}

Table 2: Distribution of cases according to age group

\begin{tabular}{|c|c|c|}
\hline Age Group & Frequency & Percentage \\
\hline $18-25$ & 9 & 30 \\
\hline $26-35$ & 3 & 10 \\
\hline $36-45$ & 16 & 53.33 \\
\hline $46-55$ & 2 & 6.66 \\
\hline Total & 30 & 100 \\
\hline
\end{tabular}

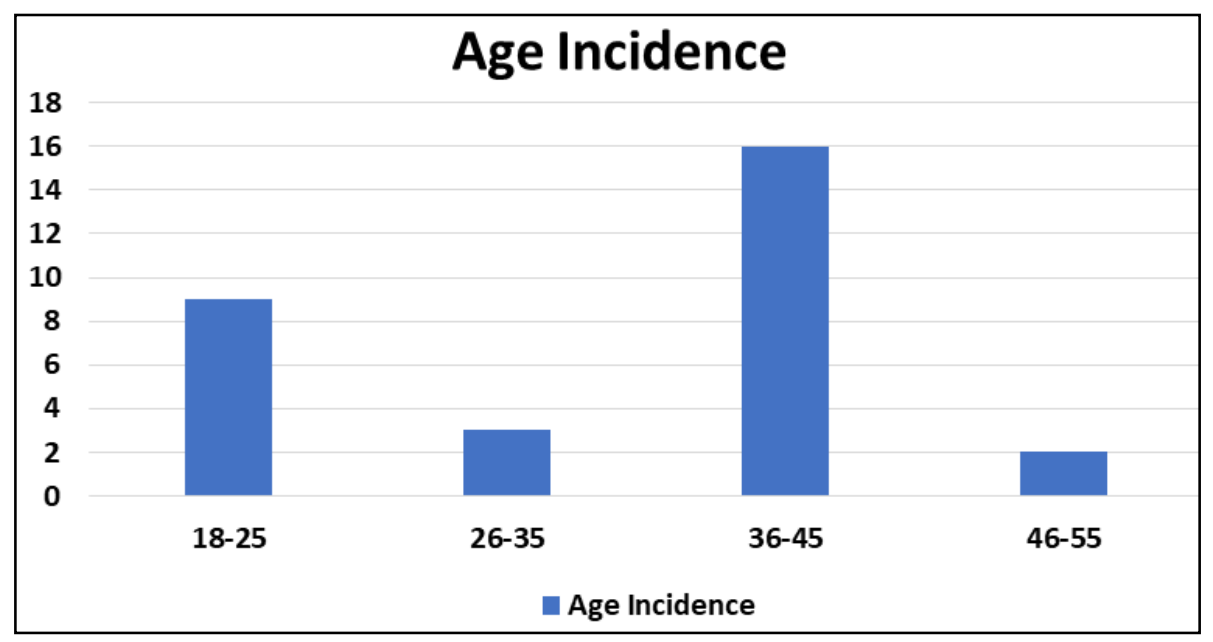

Fig 2: Distribution of cases according to age group

The highest prevalence of migraine in this study was found to be in the age group of 36-45 years with 16 cases, 9 cases in $18-25$ years, 3 cases in 26-35 years and 2 cases in $46-55$ years of age.

\subsection{Distribution of cases according to the type of migraine}

Table 3: Distribution of cases according to the type of migraine

\begin{tabular}{|c|c|c|}
\hline Type & Frequency & Percentage \\
\hline Common & 20 & 66.66 \\
\hline Classical & 10 & 33.33 \\
\hline Total & 30 & 100 \\
\hline
\end{tabular}

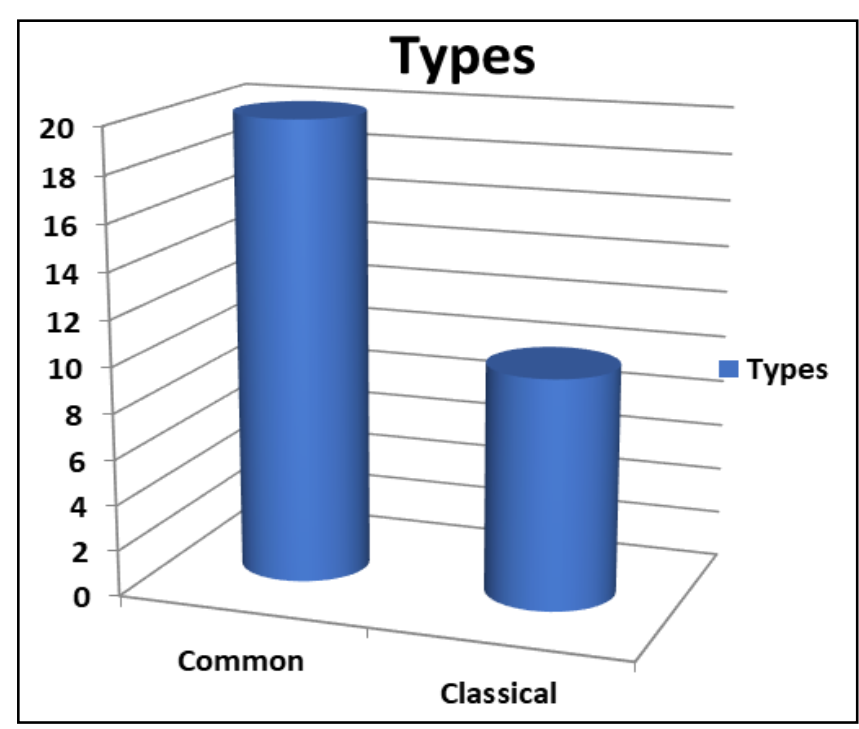

Fig 3: Distribution of cases according to types of migraine

Out of 30 cases in the study, 20 were common migraine $(66.66 \%)$ and 10 were classical migraine $(33.33 \%)$.
4.4 Distribution of cases according to the remedies administered4

Table 4: Distribution of cases according to the remedies administered

\begin{tabular}{|c|c|c|c|}
\hline SI. No & Remedies & Frequency & Percentage \\
\hline 1. & Argentum Nitricum & 1 & 3.33 \\
\hline 2. & Bryonia Alba & 2 & 6.66 \\
\hline 3. & Calcarea Carbonicum & 1 & 3.33 \\
\hline 4. & Calcarea Phosphoricum & 1 & 3.33 \\
\hline 5. & Lachesis & 1 & 3.33 \\
\hline 6. & Natrum Carbonicum & 1 & 3.33 \\
\hline 7. & Natrum Muriaticum & 15 & 50 \\
\hline 8. & Nux Vomica & 4 & 13.33 \\
\hline 9. & Pulsatilla & 1 & 3.33 \\
\hline 10. & Sepia & 1 & 3.33 \\
\hline 11. & Silicea & 1 & 3.33 \\
\hline 12. & Sulphur & 1 & 3.33 \\
\hline \multicolumn{3}{|c|}{} \\
\hline
\end{tabular}

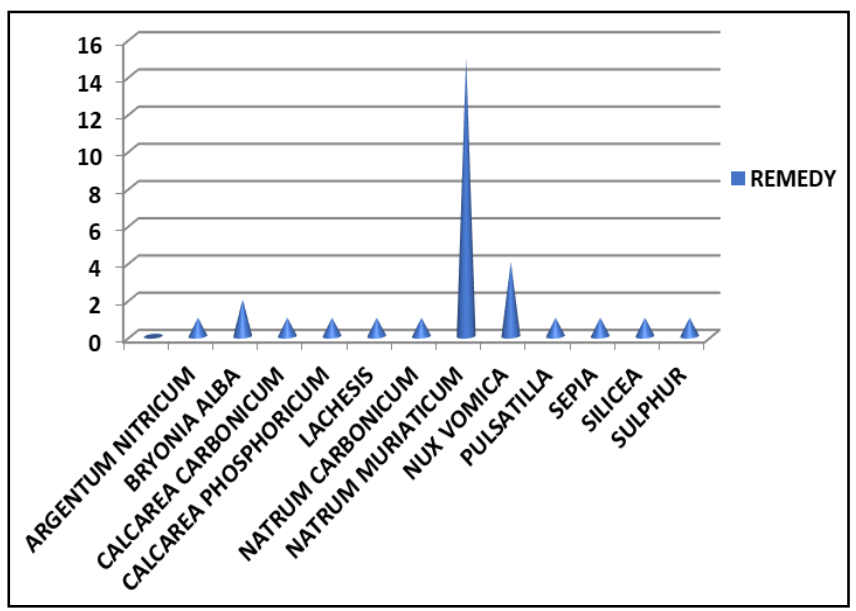

Fig 4: Distribution of cases according to the remedies administered 
Out of the 30 cases, NATRUM MUR was prescribed for 15 cases (50\%), nux vomica was prescribed for 4 cases $(13.33 \%)$ ), Bryonia Alba was prescribed for 2 cases (6.66\%), Sepia, Pulsatilla, Lachesis, Argentum nitricum, CalcPhos, Sulph, Calc carb, Natrum carb and Silicea was prescribed for 1 case $(3.33 \%)$ each.

\subsection{Distribution of cases according to occupation}

Table 5: Distribution of cases according to occupation

\begin{tabular}{|c|c|c|c|}
\hline Sl. No. & Occupation & Frequency & Percentage \\
\hline 1. & Teacher & 3 & 10 \\
\hline 2. & Student & 6 & 20 \\
\hline 3. & Housewife & 12 & 40 \\
\hline 4. & Technician & 2 & 6.66 \\
\hline 5. & Laundry worker & 1 & 3.33 \\
\hline 6. & Beedi roller & 3 & 10 \\
\hline 7. & Tailor & 1 & 3.33 \\
\hline 8. & Advocate & 1 & 3.33 \\
\hline 9. & Agriculturist & 1 & 3.33 \\
\hline \multicolumn{2}{|r|}{ Total } & 30 & 100 \\
\hline
\end{tabular}

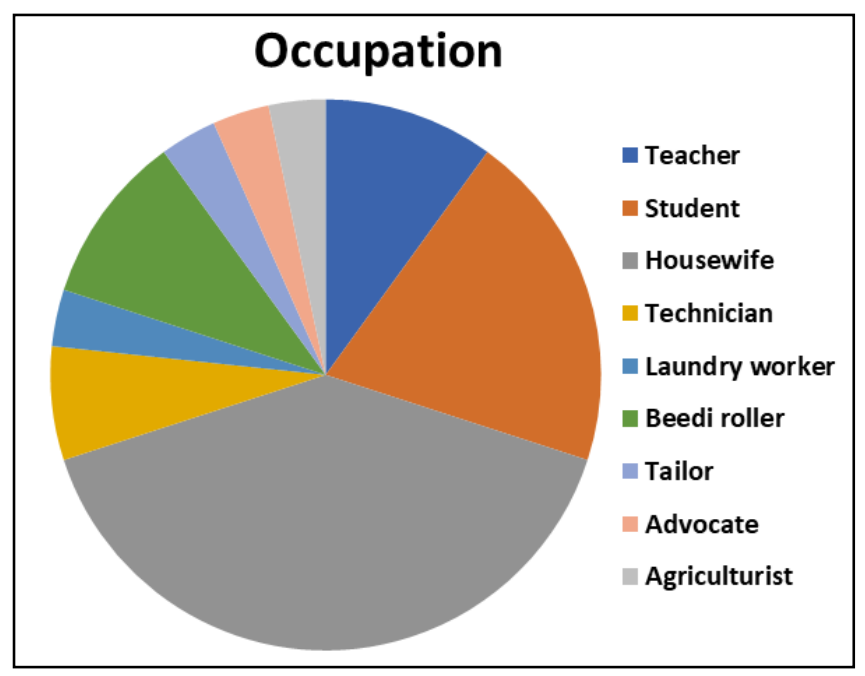

Fig 5: Distribution of cases according to the occupation

Out of the 30 cases, housewives were found to be suffering the maximum with migraine with 12 cases $(40 \%)$, students were second with 6 cases $(20 \%), 3$ cases $(10 \%)$ each of teacher and beedi roller, 2 cases $(6.66 \%)$ of technician, 1 case $(3.33 \%)$ each of laundry worker, tailor, advocate and agriculturist.

\section{Summary}

A detailed study for analyzing the effectiveness of homoeopathic medicines in treating Migraine was conducted. Cases were selected on the basis of inclusion and exclusion criteria. These cases were followed regularly for the duration of 6 months and at the end of the study, certain conclusions were attained.

Out of 30 patients, 06 were male $(20 \%)$ and 24 were female (80\%) showing female predominance in the condition.

The highest prevalence of migraine in this study was found to be in the age group of 36- 45 years with 16 cases $(53.33 \%), 9$ cases $(30 \%)$ in $18-25$ years, 3 cases $(10 \%)$ in 26- 35 years and 2 cases $(6.66 \%)$ in $46-55$ years of age.

Out of the 30 cases, NATRUM MUR was prescribed for 15 cases (50\%), nux vomica was prescribed for 4 cases (13.33\%), Bryonia Alba was prescribed for 2 cases (6.66\%),
Sepia, Pulsatilla, Lachesis, Argentum nitricum, CalcPhos, Sulph, Calc carb, Natrum carb and Silicea was prescribed for 1 case $(3.33 \%)$ each.

Out of 30 cases in the study, 20 were common migraine $(66.66 \%)$ and 10 were classical migraine $(33.33 \%)$.

Out of 30 cases 12 cases of housewives, 6 cases of students, 3 cases of teachers and beedi roller each, 2 cases of technician and 1 case of a laundry worker,

Evaluation was done based on the scores obtained from HIT- 6 Questionnaire.

All the cases (30 out of 30 i.e. 100\%) had significant improvement after the homoeopathic treatmen with "pp value $<0.001$

Thus from the analysis of all the results, it can be inferred that Homoeopathic medicines are effective in the treatment of Migraine.

\section{Conclusion}

A total number of thirty cases of Migraine (classical and common both) were taken up for the study. Conclusions were arrived after detailed study of those cases and the findings are as follows:

- A detailed case taking was done by the interview technique with the patient, which was then accessed by the physician through clinical features and physical examination. All these thirty cases were followed up for a period of 6 months.

- Out of 30 patients, 06 were male (20\%) and 24 were female $(80 \%)$

- The highest prevalence of migraine in this study was found to be in the age group of 36- 45 years with 16 cases $(53.33 \%), 9$ cases $(30 \%)$ in $18-25$ years, 3 cases $(10 \%)$ in $26-35$ years and 2 cases $(6.66 \%)$ in $46-55$ years of age.

- Out of 30 cases in the study, 20 were common migraine $(66.66 \%)$ and 10 were classical migraine $(33.33 \%)$.

- Out of the 30 cases, NATRUM MUR was prescribed for 15 cases $(50 \%)$, nux vomica was prescribed for 4 cases $(13.33 \%)$, Bryoniaalba was prescribed for 2 cases (6.66\%), Sepia, Pulsatilla, Lachesis, Argentum nitricum, CalcPhos, Sulph, Calc carb, Natrum carb and Silicea was prescribed for 1 case $(3.33 \%)$ each..

- Out of the 30 cases, housewives were found to be suffering the maximum with migraine with 12 cases (40\%), students were second with 6 cases (20\%), 3 cases $(10 \%)$ each of teacher and beedi roller, 2 cases $(6.66 \%)$ of technician, 1 case $(3.33 \%)$ each of laundry worker, tailor, advocate and agriculturist.

- After case taking, based on the totality of symptoms, remedy was administered. The HIT- 6 Questionnaire was asked to the patients during the first visit and after six months and the scores were analysed, before and after treatment

- All the cases (30 out of 30 i.e. 100\%) had significant improvement during the study with "p" value $<0.001$

Hence, the above-mentioned result is conclusive of the fact that Homoeopathic medicines are very much effective in the treatment of migraine.

\section{References}

1. Kasper DL, Braunwald E, Fauci AS. Harrison's principles of internal medicine: ${ }^{16 t h}$ edition. USA. New York: the McGraw hills companies 2005;1:88 
2. URL: http://www.who.int/whr/2001/en/: source related link. Accessed on January 10, 2018

3. URL: http://en.wikipedia.org/wiki/migraine headache: source related link. Accessed on January 10, 2018

4. URL: http://www.american migraine study.org. : source related link. Accessed on January 10, 2018.

5. Stewart WF., Lipton RB., Celentano DD., Reed ML. Prevalence of migraine headache in the united states: relation to age, income, race and other sociodemographic factors. Jama 1992;267(1):64-9

6. URL:http://www.ncbi.nlm.nih.gov/pmc/articles/PMC29 17556: source related link. Accessed on January 10 2018

7. URL:http://www.novapublishers,.com/catalog/productinfo.php?products-id=39389: source related link. Accessed on January 10, 2018

8. URL:http://www.ncbi.nlm.nih.gov/m/pubmed//1135936 : source related link. Accessed on January 10, 2018

9. URL:http://www.eurekaselect.com/144335/article.: source related link. Accessed on January 10, 2018

10. URL:http://www.google.co.in/search?q=5+hydroxy+try ptamine+in+migraine\&client.: source related link. Accessed on January 10, 2018

11. URL:http://blog.themigrainereliefcentre.com/what happens-to-dopamine-levels-during-a-migraine/.: source related link. Accessed on January 10, 2018

12. URL:http://americanmigrainefoundation.org/understand ingmigraine/thegenetics-of-migraine/: source related link. Accessed on January 10, 2018

13. URL:http://en.m.wikipedia.org/wiki/genetics-ofmigraine-headaches-: source related link. Accessed on January 10, 2018

14. URL:https://migraine.com/migraines-and-familyhistory/: source related link. Accessed on January 10, 2018

15. URL:http://migraine.com/,migraine-triggers/alcohol/.: source related link. Accessed on January 10, 2018

16. Mc Phee SJ, Papadakis MA. Current medical diagnosis \& treatment: $47^{\text {th }}$ edition. USA: the McGraw hills medicals 2008. Pg no.837

17. Boon AN, Colledge RN, Walker RB. Davidson's Principles \& Practice of medicine, $22^{\text {nd }}$ edition, UK: Churchill livingstone Elsevier, 1161-1163

18. Sainani GS. API Text book of medicine: volume 2. $10^{\text {th }}$ edition. Mumbai: Published by Association of Physicians of India 2015, 29-30

19. Kasper DL, Braunwald E, Fauci AS. Harrison's principles of internal medicine: volume $2.17^{\text {th }}$ edition. New York: the McGraw hills companies 2004, 170, 2372, 90 .

20. Kasper DL, Braunwald E, Fauci AS. Harrison's principles of internal medicine: ${ }^{16 t h}$ edition. New York: the McGraw hills companies 2004, 89p.

21. Krishnadas KV. Text Book of Medicine: $5^{\text {th }}$ edition. New Delhi: Jay pee Brothers medical publishers (P) Ltd 2008, 1224p.

22. Global burden of disease study 2013 , collaborators (22 August 2015). Global, regional and national incidence, prevalency and years lived with disability for $301 \mathrm{a} / \mathrm{c} \&$ c/c diseases and injuries in 188 countries, 1990- 2013; a systematic analysis for the global burden of disease study Lancet 2013;386(9995):743-800.

23. Fischera M, Marziniak M, Gralow I, Evers. The incidence and prevalence of cluster headache: A meta analysis of population- based studies. Cephalgia 2008;28(6):614-8. doi:10.1111/j.14682982.2008.01592.x.PMID.18422717.

24. Longmore, Murray; Ian Wilkinson; Tom turmezei; Cheekaycheung. Oxford handbook of clinical medicine, $7^{\text {th }}$ edition. Oxford university press 2007,841 .

25. URL:http://www.migrainemanagement.org.emedicine. Medscape.com/. Source related link. Acessed on February $10^{\text {th }} 2018$.

26. URL:

http://www.migrainemanagement.org.emedicine.Medsc ape.com/. Source related link. Acessed on January $10^{\text {th }}$ 2018.

27. URL:http://www.migrainemanagement.org.emedicine. Medscape.com/. Source related link. Acessed on January $10^{\text {th }} 2018$

28. Porter RS, Kaplan LJ. The merck manual of diagnosis and therapy: $19^{\text {th }}$ edition. Whitehouse (NJ): Merck sharp \& Dohmecorp, a subsidiary of merck \& co.,inc 2011, 1717-24.

29. International Headache Society. London: Sage Publication Ltd. URL: www.sagepub.co.uk

30. Golwalla AF. Medicine for students: $15^{\text {th }}$ edition. Bombay: Limaye at the Indian printing works 2013, 388p.

31. Quality Metric, Inc. and GlaxoSmithKline Group of companies 2001.

32. Clark M Kumar. Clark's Clinical medicine: $7^{\text {th }}$ edition. Printed in spain: Saunders Elsevier 2009, 1210

33. Guyton AC. Textbook of medical physiology: $11^{\text {th }}$ edition. Philadelphia: Elsevier saunders 2006, 607p.

34. Hahnemann S. Organon of medicine: $6^{\text {th }}$ edition. Kolkata: Modern Homeopathic Publication 2006.

35. Journal-Bhatt DK, Ramachandran R, Gupta S, Olesen J. The journal of headache and pain. $4^{\text {th }}$ European headache and migraine trust international congress,. Adi BS. Efficacy of homoeopathic medicines in chronic low back pain: a clinical study. International Journal of Alternative and Complementary Medicine. 2020, 17-20. EHMTIC- 2014. 18 ${ }^{\text {th }}$ September 2014;15(Supplement $1)$.

36. Baneerjee SK. Miasmatic prescribing-its philosophy, diagnostic classifications, clinical tips, miasmatic repertory, miasatic weightage of medicines and case illustrations. $2^{\text {nd }}$ extended edition. New Delhi: B. Jain publishers (P) Ltd. 2006.

37. Choudhary H. Indications of miasm. Reprint edition. New delhi: Jain publishers (P) Ltd 1995, 19-20, 44, 60, 683-684.

38. Dhawale ML. Principles and practice of homeopathy. Part-1. $3^{\text {rd }}$ edition. Bombay: Institute of clinical research 2000.

39. Kent JT, Lectures on homeopathic philosophy. Reprint edition. New Delhi: Indian books and periodicals publishers 2004.

40. Koppikar SP. Clinical experience of seventy years in homeopathy, Reprint edition. New Delhi: B. Jain publishers (P) Ltd 2004.

41. Mondal TC. A treatise on organon of medicine, Part-3. $2^{\text {nd }}$ revised edition. New Delhi: B. Jain publishers $(\mathrm{P})$ Ltd 2006, pg no. 316

42. Speight Phyllis. Comparision of chronic miasms. Reprint edition. New Delhi: Jain publishing co. 12-15.

43. Lawrence MT, Stephan JM. Current medical diagnosis 
and treatment. $47^{\text {th }}$ edition. United States of America. McGraw hill medical publishers 837-39.

44. Goldman L., Ausiello D., Cecile medicine. $23^{\text {rd }}$ Indian reprint edition. New Delhi. Elsevier 2007, 2640-2642.

45. Sarkar BK. Hahnemann's Organon of Medicine.10th ed. India: Birla Publications Pvt Ltd.

46. Kapse A. ICR Operational Manual. $3^{\text {rd }}$ ed.2011. India: Indian Books and Periodicals Publishers 69, 90, 92. 